Jurnal Anifa: Studi Gender dan Anak

Volume 2 No. 2, (November 2021) 89-97

P ISSN 2745-7648 | E ISSN 2745-763X

DOI: 10.32505/anifa.v2i1.3547

https://journal.iainlangsa.ac.id/index.php/anifa/index

\title{
KONFORMITAS GENDER: KAUM GAY DI RUANG PUBLIK SYARIAH
}

\author{
Sri Widari \\ Universitas Muhammadiyah Sumatera Utara (UMSU) Medan, Indonesia \\ sriwidari71@gmail.com
}

\begin{tabular}{ccc}
\hline Received & Revised & Accepted \\
June 04, 2021 & November 15, 2021 & November 25, 2021 \\
\hline
\end{tabular}

\begin{abstract}
Culturally the gay phenomenon has existed in the historical record of culture in Indonesia. The spread of gays in the country will continue to grow, not even closing the possibility of venturing into sharia circles, including Aceh. The existence of gay people in Langsa city caused a variety of strong reactions in the community. The phenomena ultimately force gays to camouflage in people's lives with conformity that is played slickly and massively. This research is intended to obtain answers about gay conformity in interacting in the sharia earth of Langsa City. Using qualitative descriptive measures, it was found that most gays in Langsa City always strive to demonstrate gender conformity to hide their true identity from the wider community. This is done to realize a sense of security and as a existed self-protection against discriminate people of Langsa City who uphold the values of Islamic sharia. So that with the gender conformity carried out by gays in Langsa city will create a calm because gays will feel protected from all prejudices and suspicions of the community.
\end{abstract}

Keywords: Conformity, Gay, Gender, Sharia

\begin{abstract}
Abstrak
Secara kultural fenomena gay telah ada dalam catatan sejarah kebudayaan di Indonesia. Persebaran gay di tanah air kian hari akan terus bertambah, bahkan tidak menutup kemungkinan akan merambah dalam kalangan syariah sekalipun, termasuk Aceh. Keberadaan kaum gay di Kota Langsa menimbulkan berbagai macam reaksi keras di tengah masyarakat. Femomena tersebut pada akhirnya memaksa para gay untuk berkamuflase dalam kehidupan masyarakat dengan konformitas yang dimainkan secara apik dan massif. Penelitian ini dimaksudkan untuk memperoleh jawaban tentang konfromitas gay dalam berinteraksi di bumi syariah Kota Langsa. Dengan menggunakan pendektan deskriptif kualitatif, ditemukan bahwa sebagian besar gay yang berada di Kota Langsa selalu berupaya untuk menunjukkan konformitas gender demi menyembunyikan identitas aslinya dari masyarakat luas. Hal dilakukan demi mewujudkan rasa aman dan sebagai wudju perlindungan diri terhadap diskriminasi masyarakat Kota Langsa yang menjunjung tinggi nilai syariat
\end{abstract}


Islam. Sehingga dengan konformitas gender yang 31 dilakukan kaum gay di Kota Langsa akan menciptakan suatu ketenangan, karena gay akan merasa terlindungi dari segala prasangka dan kecurigaan masyarakat.

Kata Kunci: Konformitas, Gay, Gender, Syariah

\section{PENDAHULUAN}

Menilik sejarah panjang kehidupan sosial kemasyarakatan di Indonesia selama ini, secara umum masyarakat Indonesia hanya mengenal dua kategori jenis kelamin pada manusia, yaitu laki-laki dan perempuan. Kedua jenis kategori ini diterapkan sedemikian rupa pada posisinya masing-masing sehingga tidak akan pernah boleh bertukar posisi satu sama lainnya. Dimana Laki-laki digambarkan dengan sikap kemaskulinannya sedangkan perempuan identik dengan sifat kefeminimannya. Kedua karakter identik ini selalu digariskan untuk menempati posisi saling berdampingan atau berpasangan. Sehingga tidak ada toleransi untuk penempatan laki-laki dengan laki-laki, atau perempuan dengan perempuan. Apalagi dalam konsep keterbalikan identitas penampilan, dimana laki-laki bersikap faminin atau perempuan bersikap maskulin. Sebagian besar masyarakat Indonesia terkadang menganggap kondisi tersebut sebagai sebuah bentuk keabnormalan yang dianggap melanggar pola aturan norma dalam kemasyarakatan.

Secara umum, dalam kultural masyarakat Indonesia saat ini, hanya ada satu orientasi seksual yang dapat diterima oleh masyarakat luas, yaitu heteroseksual. Ini merupakan ketertarikan hasrat yang wajar antara laki-laki dan perempuan. Namun, tidak bisa dipungkiri lagi bahwa ada kaum yang keadaannya dianggap "beda", yang juga hidup dan berinteraksi di tengah masyarakat. Mereka yang dianggap beda ialah mereka yang memiliki kecenderungan orientasi seksual terhadap jenis kelamin yang sama, hal tersebut lebih dikenal dengan istilah homoseksual.

Homoseksualitas selanjutnya dibagi menjadi dua bagian yaitu gay dan lesbian. Istilah lesbian digunakan sebagai penunjuk kepada seorang perempuan yang juga tertarik terhadap kaum sejenisnya. Sementara istilah gay digunakan untuk menunjukan identitas seorang laki-laki yang juga tertirk pada jenis kelamin yang sama dengannya (Oetomo, 2003). Pada kenyataannya, secara kultural fenomena gay juga telah ada dalam catatan sejarah kebudayaan di Indonesia, dalam kajian budaya pop, beberapa media seperti buku ataupun film juga pernah mengangkatnya sebagai suatu kajian sosial. Hal ini menunjukan bahwa sebenarnya persebaran gay di tanah air kian hari akan 
terus bertambah, bahkan tidak menutup kemungkinan akan merambah dalam kalangan syariah sekalipun. Menurut data yang diperoleh berdasarkan estimasi Kemenkes pada tahun 2012 silam saja terdapat 1.095 .970 gay baik yang tampak maupun tidak.Sementara, badan PBB memprediksi jumlah LGBT jauh lebih banyak, yakni tiga juta jiwa pada tahun 2011 (Syalaby, 2016).

Berdasarkan angka tersebut tidak menutup kemungkinan pula bahwa persebaran gay dapat mencakup seluruh wilayah di Indonesia, termasuk Aceh. Dengan adanya arus modernisasi yang kian meroket menjadikan sebagian besar gaya hidup masyarakat Aceh bergeser kearah yang dianggap tidak islami. Canggihnya teknologi menjadi suguhan utama masyrakat baik di kota maupun di desa. Tanpa mengindahkan nilai-nilai dan norma agama mereka berlomba-lomba dalam mengikuti arus globalisasi seperti pergaulan bebas termasuk fenomena LGBT (Lesbian, Gay, Bisex dan Transgender).

Kota Langsa, yang merupakan salah satu daerah otonomi di Provinsi Aceh, dimana masyarakatnya yang tergolong heterogen tentunya telah banyak terkena percikan api modernisasi ini. Maka dari itu, keberadaan kaum gay di Kota Langsa menimbulkan berbagai macam reaksi keras di tengah masyarakat. Benteng pemisah antara kaum minoritas dan mayoritas sudah pasti tak dapat dirobohkan. Penolakan dan marginalitas dari lingkungan masyarakat ini menjadikan kaum gay terhimpit oleh rasa takut, ragu, bahkan malu untuk menunjukkan identitas seksual mereka yang sebenarnya.

Meninjau sejarah peradaban manusia, diskriminasi atau stigma dalam suatu tatanan kelompok masyarakat yang dianggap berbeda tidak pernah luput dari kajian sosial. Prinsipnya adalah selama ditemukan suatu kesempatan untuk menerawang sekecil apapun perbedaan karakteristik yang ditunjukkan oleh seorang individu, maka akan terbukalah jalan untuk menciptakan deskriminasi tersebut. Deskriminasi atau stigma yang dimaksudkan dapat terwujud dalam berbagai bentuk, termasuk dalam perlakuan yang dilakukan dengan sadar untuk ditunjukkan secara langsung kepada individu yang dianggap memiliki karekter berbeda dari anggota kelompok masyarakat kebanyakan.Termasuk dalam persoalan jati diri seorang gay (Syalaby, 2016). Dalam menjalankan kehidupan sosial kemasyarakatannya sebagai makhluk sosial, seorang gay selalu merasa sulit untuk dapat hidup tanpa diberikan stigma negative dan perlakuan deskriminatif dari masyarakat kebanyakan yang memegang teguh prinsip hoteroseksual sebagai satu-satunya orientasi yang berada dalam koridor normal dan layak dalam kehidupan manusia di bumi.

Orientasi seksual yang dimiliki oleh kaum gay di Kota Langsa kerap dianggap sebagai suatu tingkah laku menyimpang yang tercela. Hal ini berdasarkan norma kesusilaan dan prinsip syariat Islam yang dipegang teguh 
oleh masyarakat Kota Langsa, sesuai dengan firman Allah dalam surat An-Nisa ayat: 1 .

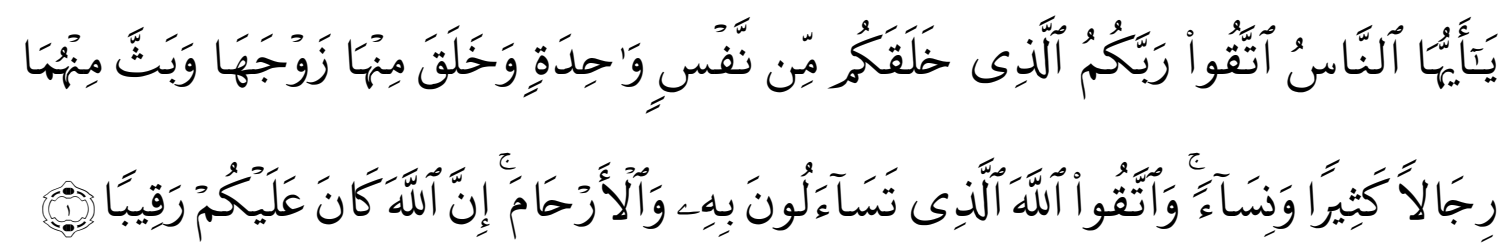

Artinya:

"Wahai manusia, bertakwalah kepada Tuhanmu yang telah menciptakan kamu dari diri yang satu (Adam), dan (Allah) menciptakan pasangannya (Hawa) dari (diri)nya; dan dari keduanya Allah memperkembangbiakkan laki-laki dan perempuan yang banyak. Bertakwalah kepada Allah yang dengan nama-Nya kamu sering meminta, dan (peliharalah) hubungan kekeluargaan.Sesungguhnya Allah selalu menjaga dan mengawasimu".(QS An-Nisa ayat 1) (RI, 2006).

Berdasarkan ayat tersebut diatas, dapat dipahami bahwa, secara fitrah seorang manusia hidup saling berpasangan-pasangan dengan lawan jenis. Sehingga penyimpangan terhadap ayat ini merupakan sebuah dosa besar yang menyalahi fitrah manusia. Hal ini memberi kesepakatan terhadap perspektif masyarakat Kota Langsa bahwa penyimpangan yang dilakukan oleh kaum gay merupakan sebuah tindakan negative yang harus dimusnahkan, karena khawatir akan menjangkiti individu lainnya yang terpengaruh oleh faktor lingkungan dan sosial.

Femomena tersebut pada akhirnya memaksa para gayyang ada di Kota Langsa untuk berkamuflase dalam kehidupan masyarakat dengan konformitas yang dimainkan secara apik dan massif. Konformitas adalah suatu proses penyesuaian diri pada seseorang untuk menyesuaikan diri terhadap normanorma yang dianut oleh suatu kelompok kemasyarakatan. Hal ini dilakukan semata-mata demi penyesuaian diri agar dapat diterima dalam suatu kelompok tertentu. Sehingga seorang individu tidak hanya terpaksa untuk berperilaku seperti orang lain, bahkan juga dipengaruhi oleh bagaimana orang lain berperilaku dalam kelompok tersebut (H. Anurawan, 2014).

\section{TINJAUAN PUSTAKA}

\section{Konformitas}

Konformitas merupakan suatu kecenderungan perilaku sosial yang dilakukan demi mempengaruhi tindakan perilaku pada diri seorang individu untuk melakukan suatu perbuatan yang menyamai tindakan dari kesepakatan suatu kelompok sesuai dengan norma yang ada. Konformitas merupakan suatu 
upaya yang dilakukan seseorang untuk mengubah sikap dan tingkah lakunya, serta menyamakan sikap dan pola pikir dalam kehidupan sosialnya agar sesuai dengan norma perilaku kelompoknya sehingga dapat diterima dalam suatu kelompok yang dimaksud dan terhidar dari celaan dan hinaan karena dianggap berbeda dari anggota kelompok lainnya (Baron, 2005).

Konformitas akan terjadi ketika sebagian besar orang dalam suatu kelompok mengatakan atau melakukan suatu tindakan yang diyakini secara benar, dan selanjutnya turut diyakini pula oleh para anggota kemlompok lainnya yang menyepakati perbuatan tersebut secara sadar. Dari beberapa pengertian di atas, dapat dirumuskan bahwa konformitas merupakan suatu perubahan sikap dan perilaku yang ditunjukkan oleh seseorangakibat dari pengaruh sosial dan berbagai tekanan anggota kelompok kemasyarakatan yang dilakukan secara sadar dan nyata. Secara garis besar, terdapat beberapa aspek yang sangat berpengaruh dalam sebuah konformitas, di antaranya adalah:

a. Kepercayaan Terhadap Kelompok

Dalam kehidupan kelompok sosial kemasyarakatan, ketika semakin besar suatu kepercayaan individu terhadap sebuah kelompok sosial yang dijadikan sebagai acuan sumber informasi, maka akan semakin besar pula kemungkinan yang dilakukan individu untuk menyesuaikan diri terhadap kelompok tersebut.

b. Kepercayaan Diri yang Lemah

Seorang Individu yang memiliki rasa percaya diri yang cenderung lemah, akan lebuh rentan untuk terepngaruh dengan kehidupan sosial kelompok yang diyakininya. Sehinggaakan meningkatkan konformitas individu tersebut agar dapat diterima dalam kelompok yang diinginkannya.

c. Antisipasi Deskriminasi Sosial

Tidak dapat disangkal bahwa orang dengan pola pikir dan perilaku berbeda dari kebanyakan orang pada umumnya sering mendapat perlakuan yang tidak adil bahkan dikucilkan dalam kehiduoan sosial. Untuk itulah ada banyak orang yang dengan sengaja melakukan konformitas demi mendapatkan pengakuan dan persetujuan untuk dapat bergabung dalam kelompok tertentu dan terhindar dari celaan atau deskriminasi sosial.

d. Rasa Takut

Pada kebanyakan tatanan sosial dalam suatu kelompok, para anggota yang enggan untuk mengikuti dan meyakini suatu aturan berlaku di dalam kelompok biasanya akan menanggung resiko yang tidak menyenangkan, untuk itulah konfromitas dialkukan oleh individu (Sh.ely E, 2009). 


\section{Gay}

Istilah gay merupakan istilah yang diciptakan pada tahun 1896 oleh ahli bidang ilmu psikiatri di Eropa untuk mengacu pada suatu fenomena yang berkonotasi klinis.Istilah ini berasal dari bahasa Jerman yang berarti bengkok, miring atau salah (Oetomo, 2003). Berdasarkan PPDGJ (Pedoman Penggolongan Diagnosis Gangguan Jiwa) gay dapat diartikan sebagai rasa ketertarikan perasaan kasih sayang, hubungan emosional, dan atau secara ekslusif terhadap orang-orang yang berjenis kelamin sama dengan atau tanpa berhubungan fisik (Kartono, 1989). Lebih jauh, para ahli mendefinisikan gay secara beragam. Menurut Deti Riyanti dan Sinly Evan Putra, gay dapat diartikan sebagai kelainan terhadap orientasi seksual yang ditandai dengan timbulnya rasa suka dari seorang pria terhadap orang lain yang mempunyai jenis kelamin sama. Sedangkan Kaplan mengemukakan bahwa gay adalah penyimpangan psikoseksual dimana seorang pria dewasa tertarik gairah seksualnya dengan teman sejenis.

Berbeda dengan pendapat diatas yang menganggap bahwa gay merupakan sebuah penyimpangan atau kelainan, Dali Gulo mengatakan bahwa gay merupakan kecenderungan pria untuk memiliki hasrat seksual atau mengadakan hubungan seksual dengan jenis kelamin yang sama. Suharko Kasran berpendapat bahwa gay pada dasarnya merupakan ketertarikan afektif dan genital terarah seorang pria kepada sesama seks (Al-Ghifari, 2003). Dalam kehidupannya di masyarakat, kaum gay biasanya memiliki ciri-ciri yang membantu mereka untuk mengenali dan dikenali oleh sesama gay dan di dalam lingkungan masyarakat. Ciri-ciri tersebut terkadang sengaja dibentuk oleh mereka, tapi ada juga yang dilakukan secara tidak sengaja atau pembawaan secara naluri.Gay lebih menyukai mengenakan pakaian ketat, karena dapat memperlihatkan lekuk tubuh si pemakai. Bagi gay, lekukan tubuh merupakan daya jual tersendiri untuk dapat menarik perhatian dari orang lain. Sedangkan gay pasif biasanya lebih senang memakai warna mencolok. Dalam berkomunikasi gaya bicaranya pun lebih feminim dan perhiasan yang dikenakannya pun cenderung ramai, bahkan itu merupakan alat komunikasi sesama gay. Ciri lainnya adalah selalu tertarik pada aktivitas yang biasanya dilakukan wanita.

\section{METODE}

Pendekatan yang akan digunakan dalam penelitian ini adalah pendekatan kualitatif (Sugiono, 2012). Sedangkan jenis penelitian yang akan digunakan dalam penelitian ini adalah jenis penelitian lapangan (field research). Adapun 
yang menjadai sumber data dalam penelitian ini adalah data segala informasi yang diperoleh dari informan yang dianggap paling mengetahui secara mendetail dan jelas mengenai fokus permasalahan yang diteliti. Maka dalam penelitian ini yang menjadi sumber data utama adalah kaum gay yang berdomisili di Kota Langsa. Dalam penelitian ini, penulis memilih untuk menggunakan teknik wawancara tidak terstruktur. Aspek yang diwawancarai adalah hal-hal yang berkenaan dengan penyesuaian diri kaum gay dalam melakukan interaksi di ruang publik syariah Kota Langsa serta segala hambatan yang dialami gay dalam membangun interaksi sosial dengan masyarakat. Analisis data dilakukan dengan tahapan mengumpulkan data, reduksi data, penyajian dan penarikan kesimpulan.

\section{HASIL PENELITIAN DAN PEMBAHASAN}

Dari keseluruhan hasil wawancara yang telah peneliti rangkum, tergambar bahwa dalam praktik sosial kemasyarakatannya seorang gay dituntut untuk memiliki keahlian dalam memainkan pernannya di tengah masyarakat. Hal ini sengaja dilakukan agar tidak mendapat kecurigaan dari masyarakat lain. Lagipula, pengakuan sebagai layaknya manusia normal juga sangat dibutuhkan oleh para kaum gay di Kota Langsa agar dapat hidup secara wajar di tengah kungkungan bumi syariat Islam.

Demi menjaga marwah palsunya di tengah masyarakat, seorang gay akan berusaha untuk menyesuaikan penampilannya yang apik sebagai pria normal di tengah masyarakat. Konformitas yang kerap dilakukan oleh para gay adalah dengan cara berlaku sebagai laki-laki yang sangat tertarik pada wanita-wanita cantik sabagaimana pria normal kebanyakan. Untuk mempertegas sisi kemaskulinannya, seorang gay juga tidak sungkan untuk melakukan kegiatan_kegiatan fisik yang banyak membutuhkan tenaga ekstra sembari membentuk postur tubuh yang banyak disukai oleh para wanita. Dengan demikian, masyarakat awam akan beranggapan bahwa hal yang demikian sengaja dilakukan demi menarik ribuan kaum hawa. Padahal dibalik konformitas yang sengaja dilakukan bukan dimaksudkan untuk menarik kaum hawa dalam pangkuan, melainkan memancing gay atau pria lainnya untuk datang mendekat.

Walaupun terkadang gay atau pria yang dituju tidak memberikan feedback sesuai yang diharapkan, namun gay mengaku akan mendapat kepuasan dan ketenangan tersendiri ketika dirinya dapat memamerkan keperkasaannya dihadapan pria lain tanpa dicurigai oleh masyarakat luas. Dalam wilayah ini, gay tidak bisa menunjukkan jati diri yang sesungguhnya secara utuh kepada 
masyarakat luas, karena jika saja hal itu dilakukan maka sanksi sosial yang tidak diharapkan pasti akan menerpa kehidupannya bahkan kehidupan seluruh keluarganya. Ditambah dengan sanksi keagamaan yang menjadi landasan utama bagi masyarakat Kota Langsa menjadikan ruang gerak gay dalam menunjukan jati dirinya akan semakin sempit dan terbatas.

Meninjau lebih dalam pengaruh aspek kesepakatan dalam konsep konformitas, adanya suatu kesepakatan yang diyakini dengan kuat dalam suatu kelompok kemasyarakatan ini dimanfaatkan sebagai acuan bagi kaum gay dalam menunjukan sikap dan perilaku maskulin yang wajar. Sehingga kondisi tersebut tentunya memiliki peranan yang kuat dalam pemberian tekanan terhadap pembentukan pribadi kaum gay di tengah masyarakat yang ada di Kota Langsa, sehingga setiap gay yang ada di Kota Langsa harus mengikuti dengan patuh setiap kesepakatan kelompok yang telah dibuat untuk mendapatkan citra maskulin yang digariskan oleh masyarakat sebagai suatu norma tidak tertulis yang disepakati bersama.

Sebagian besar gay di Kota Langsa selalu berupaya untuk menunjukkan konformitas gender demi menyembunyikan identitas aslinya sebagai seorang gay dari masyarakat luas. Hal ini terpaksa dilakukan mengingat pandangan masyarakat Kota Langsa yang menjunjung tinggi nilai syariat Islam. Dengan demikian, konformitas gender yang dilakukan kaum gay di Kota Langsa akan menciptakan suatu ketenangan, karena gay akan merasa terlindungi dari segala prasangka dan kecurigaan masyarakat yang mendeskriminasi perilaku gay.

\section{KESIMPULAN}

Konformitas diri yang dilakukan oleh kaum gay di Kota Langsa cenderung dilakukan secara massif dan apik. Hal ini dilakukan demi menjaga marwah diri dan keluarga di tengah masyarakat yang menjungjung tinggi nilai keislaman. Sehingga dengan mengikuti pola kesepakatan masyarakat yang menganggap bahwa pria normal harus tampil maskulin dan gagah, maka jati diri seorang gay tidak akan terdeteksi dengan mudah bagi masyarakat awam. Walaupun dalam prakteknya gay tidak bisa menunjukkan jati diri (orientasi seksual) yang sesungguhnya secara utuh kepada masyarakat luas. Konformitas ini dilakukan agar kaum gay di Kota dapat terhindar dari sanksi sosial yang berlaku di bumi syariat Islam, Kota Langsa. Selain itu, pengakuan diri dari masyarakat sebagai makhluk suci juga sangat dibutuhkan oleh setiap kaum gay agar tetap dapat menjalani kehidupan sosial layaknya manusia normal. 


\section{DAFTAR PUSTAKA}

Al-Ghifari. (2003). Gelombang Kejahatan Seks Remaja Modern. Mujahid Press.

Baron, R. A. (2005). Psikologi Sosial. Erlangga.

H. Anurawan, F. (2014). Psikologi Kelompok. FTK Banten Press.

Kartono, K. (1989). Psikologi Abnormal dan Abnormalitas Seksual. Mandar Maju.

Oetomo, D. (2003). Memberi Suara Pada Yang Bisu. Pustaka Marwa.

Republik Indonesia, T. P. M. A.-Q. D. A. (2006). Al-Qur'an dan Terjemahan. Karya Agung.

Shely E, et. al. (2009). Psikologi Sosial, ter. Tri Wibowo B.S. Prenada Media Group.

Sugiono. (2012). Metode Penelitian Kuantitatif Kualitatif dan R \& D. CV. Alfabeta.

Syalaby, A. (2016). Berapa Sbenarnya Jumlah. Gay di Seluruh. Indonesia? h.ttp:/ / nasional.republika.co.id/berita/nasional/umum/16/01/23/o1 e9ut394- berapa-sebenarnya-jumlah.-gay-di-seluruh.-indonesi 